\title{
Cytoplasmic intermediate filament protein expression in tunicate development: a specific marker for the test cells
}

\author{
Jian Wanga, Anton Karabinos ${ }^{\mathrm{a}}$, Alexander Zimek ${ }^{\mathrm{a}}$, Michael Meyer ${ }^{2)}$, Dieter Riemer ${ }^{\mathrm{a}}$, Clare Hudson ${ }^{\mathrm{b}}$, \\ Patrick Lemaire ${ }^{\mathrm{b}}$, Klaus Weber ${ }^{1 \mathrm{a}}$ \\ a Department of Biochemistry, Max Planck Institute for Biophysical Chemistry, Goettingen/Germany \\ b Laboratoire de Génétique et Physiologie du Développement, Institut de Biologie du Développement de Marseille, \\ CNRS-INSERM-Université de la Méditerrannée-AP de Marseille, Marseille/France
}

Received December 13, 2001

Received in revised version February 6, 2002

Accepted February 10, 2002

\section{Ciona intestinalis - intermediate filaments - keratins - test cells - urochordates}

The urochordate Ciona intestinalis is a well established system for embryological studies, and large scale EST sequences begin to emerge. We cloned five cytoplasmic intermediate filament (IF) cDNAs and made specific antibodies to the recombinant proteins. Self-assembly studies and immunofluorescence microscopy were used to study these proteins and their distribution. Confirming and extending previous studies in Styela, we found that Ciona protein IF-A is expressed in muscle and forms homopolymeric filaments while proteins IF-C and IF-D, which form only obligatory heteropolymeric filaments, resemble a keratin pair exclusively found in the entire epidermis. Protein IF-B and the new protein IF-F potentially reflect tunicatespecific IF proteins. They are found in the entire internal epithelia including the neural gland. We also extended the analysis to earlier developmental stages of Ciona. Protein IF-A is expressed in muscle from larval stages, whereas proteins IF-C and IF-D are found only in the tail epidermis. Protein IF-F is detected abundantly in the test cells of eggs, embryos and premetamorphic larvae. Our studies show that IF proteins could prove very useful markers in the study of cell fate determination in Ciona. They also support previous findings on the evolutionary relationships of different IF proteins. Non-vertebrate chordates have IF proteins which represent orthologs of vertebrate type I to III proteins, but also IF proteins that do not seem to fit into these classes. However, the intron positions of all tunicate IF genes are conserved with vertebrate type I to III genes, pointing to a common evolutionary origin.

\footnotetext{
1) Dr. Klaus Weber, Department of Biochemistry, Max Planck Institute for Biophysical Chemistry, Am Fassberg 11, D-37077 Goettingen/Germany, e-mail: office.weber@mpibpc.gwdg.de, Fax: +495512011578 .

2) Present address: Swiss Federal Institute of Technology, Institute of Cell Biology, Hönggerberg, CH-8093 Zürich/Switzerland.
}

\section{Introduction}

The multigene family of proteins forming the cytoplasmic intermediate filaments (IF) covers at least 62 members in man (reviewed in (Hesse et al., 2001)). A predominantly cytoskeletal role of IF in cellular resistance to mechanical stress emerged once human skin fragility syndromes were connected with mutations in epidermal keratin genes. Today mutations in 16 keratin genes are associated with human diseases (for review see (Irvine and McLean, 1999)). A recent RNA interference study in Caenorhabditis elegans shows that at least four of the 11 cytoplasmic IF proteins are essential in nematode development (Karabinos et al., 2001a).

All IF proteins are based on a common structure. Variable head and tail domains flank the central $\alpha$-helical rod domain which can form a double-stranded coiled coil. Based on sequence similarities, biochemical properties, tissue-specific expression patterns and the organisation of the corresponding genes the vertebrate IF proteins are conveniently divided into 5 subfamilies. Type I and II proteins are keratins which together give rise via a hetero coiled coil to the obligate heteropolymeric keratin filaments of epithelia and epidermal appendages. The type III group covers the mesenchymally derived IF proteins desmin, vimentin, peripherin and GFAP, which in vitro can form homopolymeric IF. Five neuronal IF proteins form the type IV while the nuclear lamins are type V IF proteins (for review see (Fuchs and Weber, 1994; Parry and Steinert, 1995; Herrmann and Aebi, 2000)). Interestingly, orthologs of type I to III IF proteins are also documented for the cephalochordate Branchiostoma (Karabinos et al., 2000; 2001b) and the urochordate (tunicate) Styela (Riemer and Weber, 1998; Wang et al., 2000). Thus the Styela IF proteins C and D, which are coexpressed in the epidermis, were identified as type II and type I keratin orthologs, respectively. Just like vertebrate keratins they show obligatory heteropolymeric filament formation. In 
spite of the strong sequence drift Styela IF protein D shows chimeric IF assembly with human keratin 8 , a type II keratin. Use of mutant proteins showed that these filaments are based on a hetero coiled coil. In addition, Styela has also a musclespecific and homopolymeric filament-forming protein A which is an ortholog of the vertebrate type III protein desmin. Finally, the Styela IF protein B is found in interior epithelia and shows very poor ability to form homopolymeric IF (Wang et al., 2000).

In contrast to the cytoplasmic IF proteins of the chordates the IF proteins of protostomic animals show two structural changes, which document an even closer relation to the nuclear lamins. They all have, like the lamins, a coil $1 \mathrm{~b}$ subdomain, which is increased by 42 residues or 6 heptads and they often show a lamin homology segment of 105 residues in their carboxyterminal tail domains (Erber et al., 1998; Weber et al., 1989).

In order to further understand the evolution of this important class of proteins we have extended our analysis of urochordate cytoplasmic IF proteins to Ciona intestinalis. This tunicate is of particular interest in embryological studies (Corbo et al., 2001), and there is the aim to establish large-scale EST sequence data sets from different developmental stages (see (Satou et al., 2001)). In addition Ciona intestinalis is readily available in most seas and oceans. Here we describe the cloning of five Ciona cytoplasmic IF proteins of which four, proteins IF-A, IF-B, IF-C and IF-D, had been previously isolated from Styela (Wang et al., 2000). The fifth, protein IF-F, represents a previously unknown IF protein type. The filament self-assembly features, the gene structures and the tissue-specific expression patterns of all five proteins in adults, juveniles, larvae and embryos are reported in this study.

\section{Materials and methods}

\section{Adult animals and embryos}

Adult Ciona intestinalis were from Helgoland in the North Sea or Roscoff, France. Animals were either frozen in liquid nitrogen and stored at $-80^{\circ} \mathrm{C}$ until use or were maintained under constant light at $16^{\circ} \mathrm{C}$ in sea water. Eggs and sperm were surgically collected from the gonoducts of 4-5 animals. After cross-fertilization, excess sperm was washed away. Non-dechorionated embryos were raised at $16^{\circ} \mathrm{C}$ in natural sea water. Different pre- and post-metamorphic developmental stages were collected and briefly centrifuged at low speed. The embryo pellets were either used for whole-mount immunofluorescence experiments or embedded in Tissue-Tek for cryosections and immediately frozen at $-80^{\circ} \mathrm{C}$.

\section{Ciona cDNA libraries}

Ganglion and intestine were separately dissected. mRNA was prepared from the frozen specimen by homogenization in Trizol reagent (Gibco BRL, Eggenstein, Germany) according to the manufacturer's instructions. Poly(A) ${ }^{+}$RNA was isolated as described (Dodemont et al., 1994). Synthesis of cDNAs and construction of phage libraries were performed with the Zap Express Kit (Stratagene, Heidelberg, Germany).

\section{Isolation of Ciona intestinalis IF cDNA clones}

Screening of the $\lambda$ ZapII cDNA expression libraries using the murine IFA antibody was performed as described (Erber et al.,1998). Screening of cDNA libraries with DIG-labeled cDNA probes comprising the entire rod domains of Styela clava or Ciona intestinalis IF proteins at reduced stringency was done according to (Wang et al., 2000). The five isolated IF clones (A, B, C, D, F) were amplified by PCR with T3 and T7 primers and the resulting PCR products were cloned into the pCR2.1 vector (Invitrogen, Leek, The Netherlands). All inserts were completely sequenced on both strands (MWG-Biotech., Ebersberg, Germany).
These cDNA sequences are available from the EMBL/GenBank under accession numbers for IF-A (AJ298329), IF-B (AJ298330), IF-C (AJ298331), IF-D (AJ298332) and IF-F (AJ298333).

\section{Intron mapping of Ciona IF-C, IF-D and IF-F genes}

Genomic DNA was extracted from individual adult animals as described (Riemer et al., 1998). PCR was used to amplify the relevant fragments from the genomic DNA using 100 ng of genomic DNA as template for each PCR reaction. Primer sequences and positions (sense/antisense ) in the respective cDNAs were as follows: IF-C, nt 29-53/434-408, 408434/800-774, 776-803/1136-1113, 1115-1138/1385-1359; IF-D, nt $7-33 / 366-340,340-366 / 684-658,664-688 / 1052-1026,1034-1060 /$ 1424-1399; IF-F, nt 7-30/216-190, 182-208/458-433, 442-467/770745, 735-761/1064-1039, 1030-1055/1276-1252. All PCR fragments were cloned into the pCR 2.1 vector (Invitrogen) and subjected to sequence analysis.

\section{Expression and purification of Ciona IF recombinant proteins}

The entire coding regions of the five Ciona IF cDNA clones (A, B, C, D, F) were amplified by PCR with the following primers (unique restriction sites are underlined; the primer positions in nucleotides refer to the corresponding cDNA sequences): IF-A (NdeI/BamHI): 5'-TAACAAG GTAACCTCCATATGGCGCAAAGGAGCAGC-3' (sense, nt 8-43), 5'-AATTGTTTTTAAATAGGATCCATTGTTGCTCACAAGGTG GCG-3' (anti-sense, nt 1617-1576). IF-B (NcoI/EcoRI): 5'-CTCCAGT CAAGAACGAAACCATGGATTCTTCCG-3'(sense, nt 61-93) and 5'-CCCTCGTGAATTCATTAGATCTCGCTCTCCG-3' (anti-sense, nt 1420-1390). IF-C (NdeI/EcoRI): 5'-CTCGGACCATATGCAGTC AACGGCAGGAC-3' (sense, nt 6-34) and 5'-CGGCAGAGCTTGTGAATTCTTCTCTTGGCTTTTTAAGGCG-3' (anti-sense, nt 13671328). IF-D (NdeI/BamHI): 5'-CCAATCGAAACATATGGCATCCA AGCAGGGACG-3' (sense, nt 6-38) and 5'GCGGTTTCTATGAGGATCCTTTCTTATTTTACTCTTCGTCGC-3' (anti-sense, nt 13691328). IF-F (BamHI/HindIII): 5'-AAGAAGACACTGGATCCCATG GCTCC-3' (sense, nt 5-30) and 5'-GTTTGTGGGATTAAAGCTTAT ATGATAGAGCTTAAGG-3' (anti-sense, nt 1303-1267). PCR products were digested with the appropriate restriction enzymes, gel purified and ligated in frame usually into the pET23a ${ }^{+}$vector (Novagen, USA). The IF-B product was inserted into the pKK388-1 vector (Clontech). The IF-F product with an N-terminal histidine tag was cloned into the pRSET-B vector (Invitrogen). All recombinant IF proteins were expressed in E. coli BL21 (DE3) pLysS (Novagen) as described (Wang et al., 2000).

The recombinant proteins were highly enriched in inclusion body preparations. These were dissolved in $8 \mathrm{M}$ urea, and the IF proteins were purified by ion exchange chromatography in urea buffer (Wang et al., 2000). Protein purity was monitored by SDS-PAGE. The N-terminal sequences of the purified recombinant proteins were verified by automated Edman degradation. Self assembly was induced by dialysis of the urea-containing solutions against filament buffer as described (Wang et al., 2000).

\section{In vitro filament assembly}

Aliquots of purified recombinant proteins $(0.2-0.3 \mathrm{mg} / \mathrm{ml})$ in $8 \mathrm{M}$ urea were dialysed at room temperature against assembly buffers using dialysis filters (Millipore, Eschborn, Germany). Structures formed were analysed by electron microscopy after negative staining with $2 \%$ uranyl acetate (Wang et al., 2000).

Different dialysis conditions were used. Protein IF-A was first dialysed in $2 \mathrm{mM}$ Tris- $\mathrm{HCl}$, pH 9.0, with $1 \mathrm{mM}$ DTT for $3 \mathrm{~h}$, then changed to $10 \mathrm{mM}$ Tris- $\mathrm{HCl}$, pH 7.6, with $150 \mathrm{mM} \mathrm{NaCl}$ and $1 \mathrm{mM}$ DTT for $3 \mathrm{~h}$. Protein IF-B was dialysed in $10 \mathrm{mM}$ Tris- $\mathrm{HCl}, \mathrm{pH} 7.2$, with $1 \mathrm{mM}$ DTT for $4 \mathrm{~h}$. An equal molar mixture of proteins IF-C and IF-D was dialysed first in $10 \mathrm{mM}$ Tris- $\mathrm{HCl}$, pH 9.0, with $1 \mathrm{mM}$ DTT for $2 \mathrm{~h}$, and then in $10 \mathrm{mM}$ Tris-HCl, pH 7.4, with $1 \mathrm{mM}$ DTT for $3 \mathrm{~h}$. Protein IF-F was dialysed in $10 \mathrm{mM}$ Tris- $\mathrm{HCl}, \mathrm{pH}$ 7.0, with $1 \mathrm{mM}$ DTT for $5 \mathrm{~h}$. 


\section{Production and purification of antibodies}

Rabbit antisera were raised (BioScience, Goettingen, Germany) with the following synthetic peptides used as antigens: anti-A: CEQSSGDHDDNAHATL (aa 506-520 of IF-A in Fig. 1); anti-B: CRKVVIRKGSENDGKNS (aa 409-424 of IF-B in Fig. 1); anti-C: CSAYKNAQSKSGRKSP (aa 425-439 of IF-C in Fig. 1); anti-D: CQSRVAQLGSEFDHAQ (aa $326-341$ of IF-D in Fig. 1); anti-F: CEMLEKDTPAKEPSTV (aa 395-409 of IF-F in Fig. 1). Peptides were coupled via their extra $\mathrm{N}$-terminal cysteine to hemocyanin. All antisera were affinity purified on the immobilized peptide antigen and if necessary also preabsorbed on other recombinant proteins bound to cyanogenbromide-activated Sepharose 4B (Pharmacia, Uppsala, Sweden) as described (Wang et al., 2000). The specificity of each antibody was tested by immunoblots with all recombinant proteins and a total extract from adult Ciona intestinalis (see Results).

\section{SDS-PAGE and immunoblotting}

A single frozen adult Ciona was pulverized in liquid nitrogen. An aliquot of the homogenized powder was dissolved in $9 \mathrm{M}$ urea for $5 \mathrm{~min}$, and finally boiled in sample buffer for 3 min to provide a total Ciona extract. This extract and the purified Ciona recombinant IF proteins (A, B, C, D, F) were separated on $10 \%$ SDS-PAGE gels and transferred electrophoretically onto nitrocellulose membranes. Immunostaining with purified anti-IF antibodies (diluted 1:100) and anti-rabbit peroxidaselabeled second antibodies (diluted 1:8000; Dako, Denmark) were carried out using the ECL kit (Amersham).

\section{Immunofluorescence microscopy}

Cryosections were cut from adult Ciona animals and embryos at different developmental stages and fixed in acetone at $-20^{\circ} \mathrm{C}$. The sections were incubated with the affinity-purified anti-Ciona IF antibodies (see above; diluted 1:10 to $1: 30$ ) as described (Wang et al., 2000). Bound antibodies were detected with rhodamine-conjugated anti-rabbit secondary antibodies (diluted 1:100; Dako, Denmark). DNA was stained with Hoechst 33258. For whole-mount staining, nondechorionated embryos and later developmental stages were fixed in methanol at $-20^{\circ} \mathrm{C}$ for $10 \mathrm{~min}$ followed by antibody staining as described (Hudson and Lemaire, 2001).

\section{Results}

\section{Five cytoplasmic IF proteins cloned from adult Ciona}

The cDNA library prepared from ganglion-enriched tissue was screened first with the murine monoclonal antibody IFA which detects some but not all IF proteins (Pruss et al., 1981). This screen provided a complete cDNA clone for Ciona protein IFA (Fig. 1). A second screen, performed at reduced stringency with cDNA probes derived from the rod domains of the four Styela IF proteins (Wang et al., 2000), led to cDNAs for five Ciona IF proteins IF-A, IF-B, IF-C, IF-D, and IF-F (Figs. 1,2). The same results were obtained with a cDNA library prepared

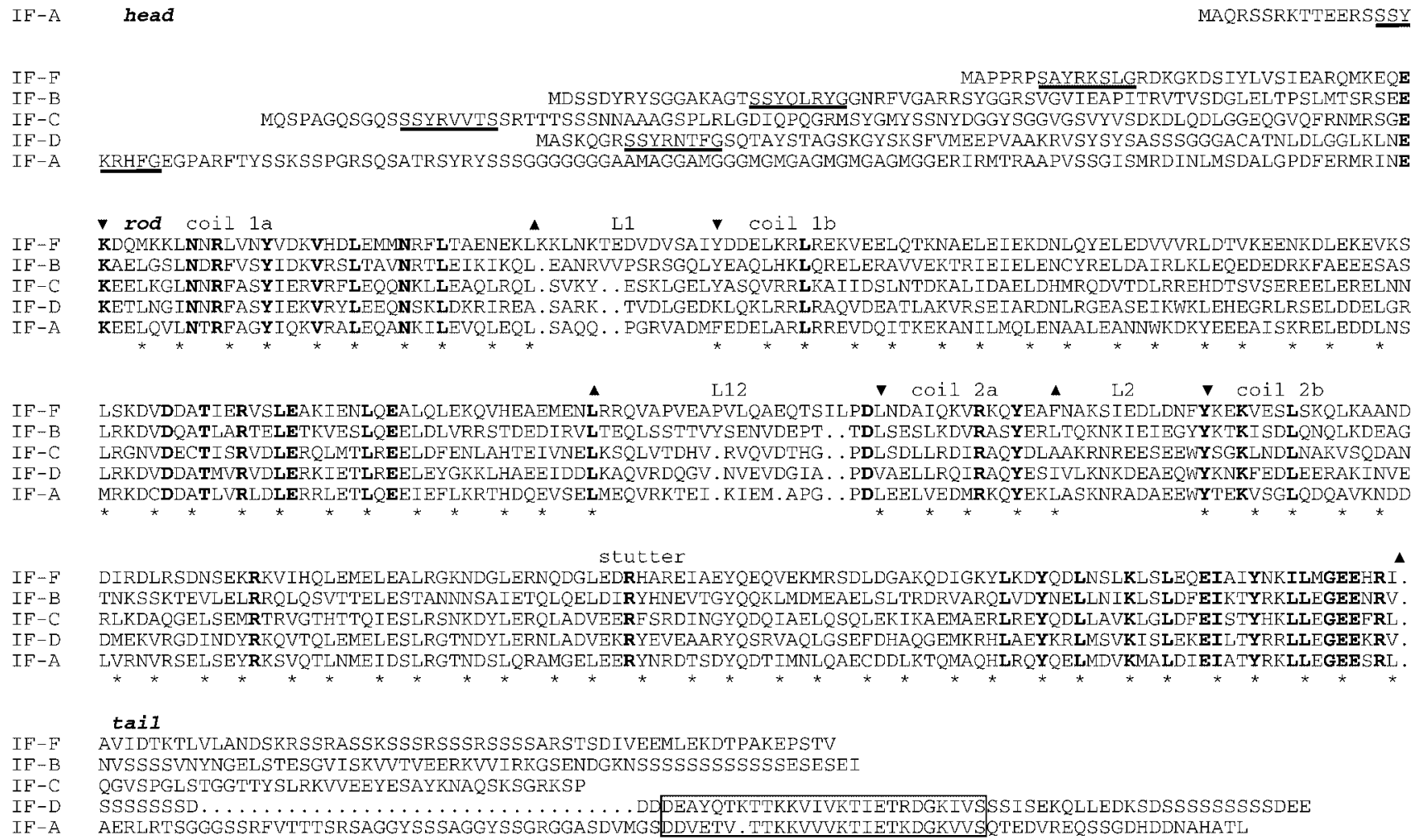

IF $-F$

IF - B

$I F-C$

$\mathrm{IF}-\mathrm{D}$

$I F-A$

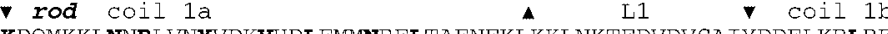

KDQMKKLNNRLVNYVDKVHDLEMMNRFLTAENEKLKKLNKTEDVDVSAIYDDELKRLREKVEELQTKNAELEIEKDNLQYELEDVVVRLDTVKEENKDLEKEVKS IF-B KAELGSLNDRFVSYIDKVRSLTAVNRTLEIKIKOL. EANRVVPSRSGOLYEAQLHKLORELERAVVEKTRIEIELENCYRELDAIRLKLEOEDEDRKFAEEESAS

IF-C KEELKGLNNRFASYIERVRFLEOONKLLEAOLROL SVKY ESKLGELYASOVRRLKAIIDSLNTDKALIDAELDHMRQDVTDLRREHDTSVSEREELERELNN

IF-D KETLNGINNRFASYIEKVRYLEEQNSKLDKRIREA. SARK. . TVDLGEDKLQKLRRLRAOVDEATLAKVRSE IARDNLRGEASEIKWKLEHEGRLRSELDDELGR

IF-A KEELQVLNTRFAGYIQKVRALEQANKILEVQLEQL . SAQQ . PGRVADMFEDELARLRREVDQITKEKANILMQLENAALEANNWKDKYEEEAI SKRELEDDLNS

IF-F LSKDVDDATIERVSLEAKIENLOEALOLEKOVHEAEMENLRROVAPVEAPVLOAEOTSILPDLNDAIOKVRKOYEAFNAKSIEDLDNFYKEKVESLSKOLKAAND

IF - B LRKDVDOATLARTFLETKVESLOEELDLVRRSTDFDIRVLTEOL SSTTVYSENVDEFT . TDL SESLKDVRA SYERLTOKNKIEIEGYYKTKI SDIONOUKDFAG

- RGNVDECT

IF-C LRGNVDECT

IF-D LRKDVDDATMVRVDLERKIETLREELEYGKKLHAEEIDDLKAQVRDQGV. NVEVDGIA. . PDVAELLRQIRAQYESIVLKNKDEAEQWYKNKFEDLEERAKINVE MRKDCDDATLVRLDLERRLETLQEEIEFLKRTHDQEVSELMEQVRKTEI. KIEM. APG. . PDLEELVEDMRKQYEKLASKNRADAEEWYTEKVSGLQDQAVKNDD

IF-F DIRDLRSDNSEKRKVIHQLEMELEALRGKNDGLERNQDGLEDRHAREIAEYQEQVEKMRSDLDGAKQDIGKYLKDYQDLNSLKLSLEQEIAIYNKILMGEEHRI. IF-B TNKSSKTEVLELRROLOSVTTELESTANNNSAIETOLOELDIRYHNEVTGYOOKLMDMEAEL SLTRDRVAROLVDYNELLNIKLSLDFEIKTYRKLLEGEENRV. IF-C RLKDAOGELSEVRTRVGTHTTOIESLRSNKDYLEROLADVEERFSRDINGYODOTAELOSOLEKTKAEMAERLREYODLLAVKLGLDFEISTYHKLLEGEEFRL. IF-D DMEKVRGDINDYRKOVTOLEMELESLRGTNDYLERNLADVEKRYEVEAARYOSRVAOLGSEFDHAOGEMKRHLAEYKRLMSVKISLEKEILTYRRLLEGEFKRV. IF-A LVRNVRSELSEYRKSVQTLNMEIDSLRGTINDSLQRAMGELEERYNRDTSDYQDT IMNLQAECDDL KTOMAQHLRQYQELMDVKMALDIEIATYRKLLEGEESRL .

IF-F AVIITKTLVLANDSKRSSRASSKSSSRSSSRSSSSARSTSDIVEEMLEKDTPAKEPSTV

IF-B NVSSSSVNYNGELSTESGVISKVVTVEERKVVIRKGSENDGKNSSSSSSSSSSSSESESEI

IF-C QGVSPGLSTGGTTYSLRKVVEEYESAYKINAQSKSGRKSP

IF-D SSSSSSSD ................. DDDEAYQTKTTKKVIVKTIETRDGKIVSSSISEKQLLEDKSDSSSSSSSSSDEE

IF-A AERLRTSGGGSSRFVTTTSRSAGGYSSSAGGYSSGRGGASDVMGSDDVETV. TTKKVVVKTIETKDGKVVSOTEDVREOSSGDHDDNAHATI

Fig. 1. Sequence alignment of five cytoplasmic IF proteins (IF-A, IFB, IF-C, IF-D and IF-F) identified in Ciona intestinalis. The three domains - head, rod and tail - typical for IF proteins are indicated. Borders of the subdomains (coil 1a, 1b, 2a, and 2b) of the central helical rod domains are marked by arrowheads pointing down and up. The length-variable non-helical linkers (L1, L12 and L2) are also indicated. Bold letters mark identical residues in all 5 sequences. Asterisks below the sequences indicate the $a$ and $d$ positions of the consecutive heptads
( $a$ to $g$ ) with the haptad stutter in the coil 2b subdomain (for details of IF structure see (Fuchs and Weber, 1994; Parry and Steinert, 1995)). The horizontal lines mark similar short sequence motifs in the head domains of all aligned IF proteins. A conserved motif in the tail domain of the IF-A and IF-D proteins is boxed. The cDNA sequences are available from the EMBL/GenBank under accession numbers IF-A (AJ298329), IF-B (AJ298330), IF-C (AJ298331), IF-D (AJ298332) and IF-F (AJ298333). 
from material enriched in intestinal tissue. Inspection of the 5 sequences showed that Ciona protein IF-A, IF-B, IF-C, and IF$\mathrm{D}$ are homologs of the four IF proteins previously cloned from Styela (Wang et al., 2000) while protein IF-F describes a new tunicate IF protein.

The phylogenetic tree calculated in Figure $2 \mathrm{~B}$ shows the five branches of tunicate cytoplasmic IF proteins. While Ciona proteins IF-D, IF-C and IF-A are functional orthologs of vertebrate I to III IF proteins the remaining proteins IF-B and IF-F are not yet understood in their relation to vertebrate IF subtypes. Figures $2 \mathrm{~A}$ and $2 \mathrm{~B}$ also incorporate results on
Molgula oculata where we cloned IF protein C (MoC) and D (MoD) from a gastrula cDNA library (accession numbers AJ417905 and AJ417906).

\section{Organization of Ciona IF genes}

We previously analysed the exon/intron patterns of the IF genes Sty-A and Sty-B of Styela (Riemer and Weber, 1998). Figure 2C extends this analysis to the Ciona genes encoding proteins IF-C, IF-D and IF-F. All tunicate IF genes have an intron pattern in which at least 4 to 6 intron positions are shared with vertebrate type I to III IF genes. In contrast, the vertebrate neurofilament
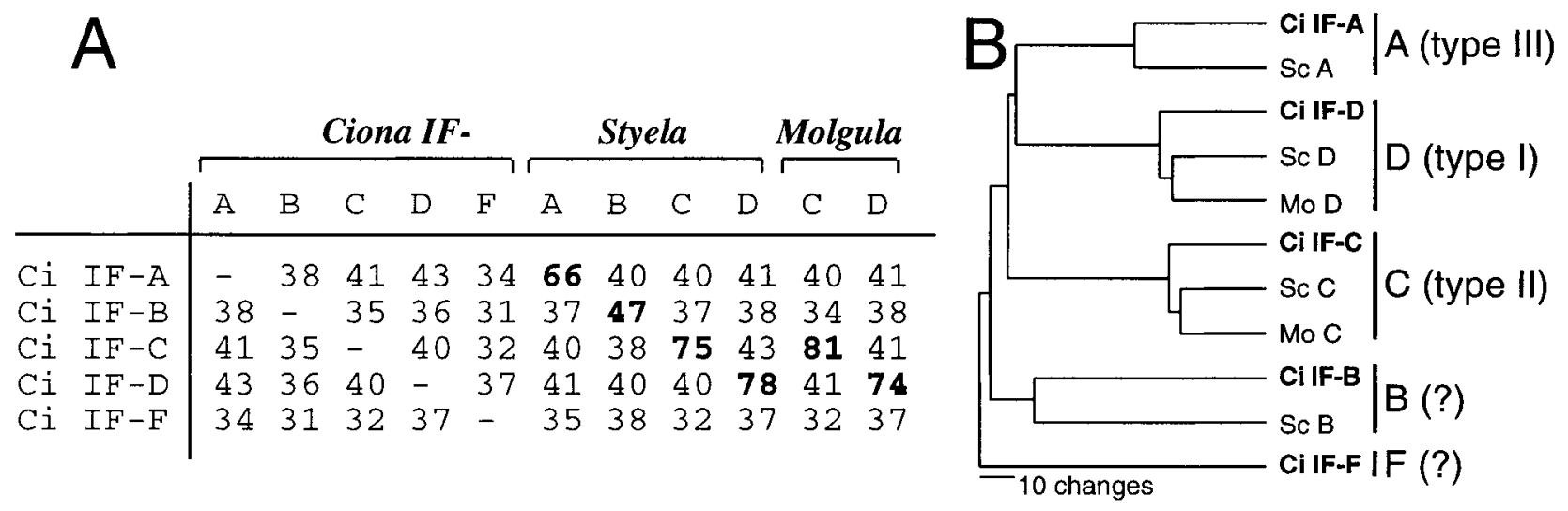

C
I: K14
II: K6
III: Des
IV: NF-H
Branch-B1
Sp A
Sp B
Ci IF-C
Ci IF-D
Ci IF-F

Fig. 2. Sequence comparison and gene structure of Ciona cytoplasmic IF proteins. (A) Identities (in percentage) for the rod domains of five Ciona intestinalis (Ci), four Styela clava (Sc; (Wang et al., 2000)) and two Molgula oculata (Mo) IF protein sequences (this study; accession numbers AJ417905 and AJ417906). IF rod sequences within the A, B, $\mathrm{C}$, and $\mathrm{D}$ subfamilies show significantly higher identities (highlighted in bold) than pairwise compared sequences from different subfamilies. Note the lower sequence identities (47\%) within the B proteins. (B) An evolutionary tree generated by the analysis of the rod domains from five Ciona, four Styela and two Molgula IF proteins. The tree was constructed using the UPGMA analysis with the program PAUP (Version V4.0b8; Swofford, 1998). The urochordate IF proteins are grouped into the five branches (A, B, C, D, and F) of which A, C and D are clearly related to a particular type of vertebrate IF proteins (see text). (C) Comparison of intron positions in tunicate and chordate IF genes. The tripartite structural organisation of the cytoplasmic IF proteins is indicated at the top. Solid and open triangles specify common and unique intron positions, respectively. Vertebrate type I to
IV genes (for references see (Dodemont et al., 1990)) are represented by human keratin 14 (I: K14), human keratin 6 (II: K6), hamster desmin (III: Des) and human neurofilament protein NF-H (IV: NF-H). The Branchiostoma B1 gene (Branch-B1; (Riemer et al., 1992)) serves as representative for the multigene family of IF proteins of the cephalochordate Branchiostoma (Karabinos et al., 2000). Gene structures of five urochordate IF genes are represented by the Styela genes SpA and $\mathrm{SpB}$ (Riemer and Weber, 1998) and the three Ciona intestinalis (Ci) genes IF-C, IF-D and IF-F (this study). All tunicate genes resemble vertebrate type I to III genes and not the type IV NF-H gene. The intron positions for the Ciona IF genes occur past the following nt numbers of the cDNA sequences (the approximate size of the introns in $\mathrm{kb}$ is given in parentheses). These are for IF-C: $\mathrm{nt} 152(0.41 \mathrm{~kb}), 306$ (0.24 kb), $546(0.69 \mathrm{~kb}), 702(0.28 \mathrm{~kb}), 864(0.34 \mathrm{~kb}), 990(0.4 \mathrm{~kb}), 1156$ $(0.15 \mathrm{~kb}), 1302(0.54 \mathrm{~kb})$; for IF-D: nt $181(0.081 \mathrm{~kb}), 279(0.24 \mathrm{~kb}), 482$ $(0.65 \mathrm{~kb}), 639(0.31 \mathrm{~kb}), 801(0.42 \mathrm{~kb}), 927(0.98 \mathrm{~kb}), 1150(0.46 \mathrm{~kb})$, $1241(0.4 \mathrm{~kb})$; for IF-F: nt $103(0.22 \mathrm{~kb}), 295(0.24 \mathrm{~kb}), 393(0.31 \mathrm{~kb}), 550$ (0.35 kb), $721(0.23 \mathrm{~kb}), 847$ (0.085 kb), $961(0.40 \mathrm{~kb}), 1068$ (0.39 kb). 
genes have only very few introns and these occur in unique positions. While vertebrate IF genes lack an intron in the head domain all five tunicate genes show such an intron position.

\section{In vitro filament assembly}

Since the sequence identity values for corresponding IF proteins from the two tunicates Styela and Ciona are only between $47 \%$ and $78 \%$ (Fig. $2 \mathrm{~A}$ ), we also analyzed the in vitro self-assembly properties of the recombinant Ciona IF proteins. As reported for Styela (Wang et al., 2000), Ciona protein IF-A formed long homopolymeric filaments (Fig. 3A) in line with its type III character. Protein IF-B was assembled into poorlooking homo-filaments (Fig. 3B). Proteins IF-C and IF-D behaved like a type II and type I keratin pair by their obligatory heteropolymeric filament assembly ability (Fig. 3C). That protein IF-D is a keratin type I ortholog was shown by the chimeric filaments formed together with human keratin 8, a type II keratin (see also Fig. 5B in (Wang et al., 2000)). The novel tunicate IF protein IF-F failed to form filaments either alone (Fig. 3D) or as a stoichiometric mixture with proteins IF$\mathrm{B}$, IF-C or IF-D.

\section{Tissue-specific expression of IF proteins in adult Ciona}

To characterize the expression pattern of the five Ciona cytoplasmic IF proteins, polyclonal anti-peptide antibodies were prepared, affinity purified and if necessary also preabsorbed on crossreacting IF proteins (see Materials and methods). The specificity of each rabbit-derived antibody is documented in immunoblots of a total Ciona protein extract and the five Ciona IF proteins IF-A to IF-F which were produced recombinantly in E. coli and purified to homogeneity using ion exchange chromatography (see Materials and methods). All antibodies recognized in immunoblots the corresponding recombinant IF protein and stained comigrating polypeptides in the total Ciona protein extract (Fig. 4).

Immunofluorescence microscopy with the purified antibodies was performed on cryosections of adult Ciona. Both IF proteins IF-C and IF-D were exclusively co-expressed in all epidermal cells (Figs. 5B,D). Protein IF-A was identified in muscle tissue (Fig. 5F) while protein IF-B was found in the entire interior epithelia including atrial epithelium, intestine and weakly also the branchial sac (Figs. 5K, 6B). These localization patterns correspond to those reported previously for the four IF proteins A, B, C and D in the tunicate Styela (Wang et al., 2000). In addition, we found strong staining for protein IF-B in the neural gland of adult Ciona (Fig. 6B). Interestingly, the new IF protein IF-F was coexpressed with protein IF-B in the various interior epithelia and in some cells of the neural gland (Figs. 5I, 6D).

\section{The expression pattern of IF proteins during Ciona development}

In order to investigate the synthesis of the five proteins during Ciona development we also stained whole embryos, larvae and juveniles with the specific anti-Ciona IF antibodies. As in adults, expression of the desmin homologue, protein IF-A was detected in larval tail muscles (Figs. 7A-C) as well as in juvenile body wall muscles (not shown). Interestingly, both the epidermal IF proteins IF-C (Figs. 7D-F) and IF-D were restricted to the tail epidermis of larvae. In juveniles, protein IF-C and IF-D were found throughout the entire epidermis (not

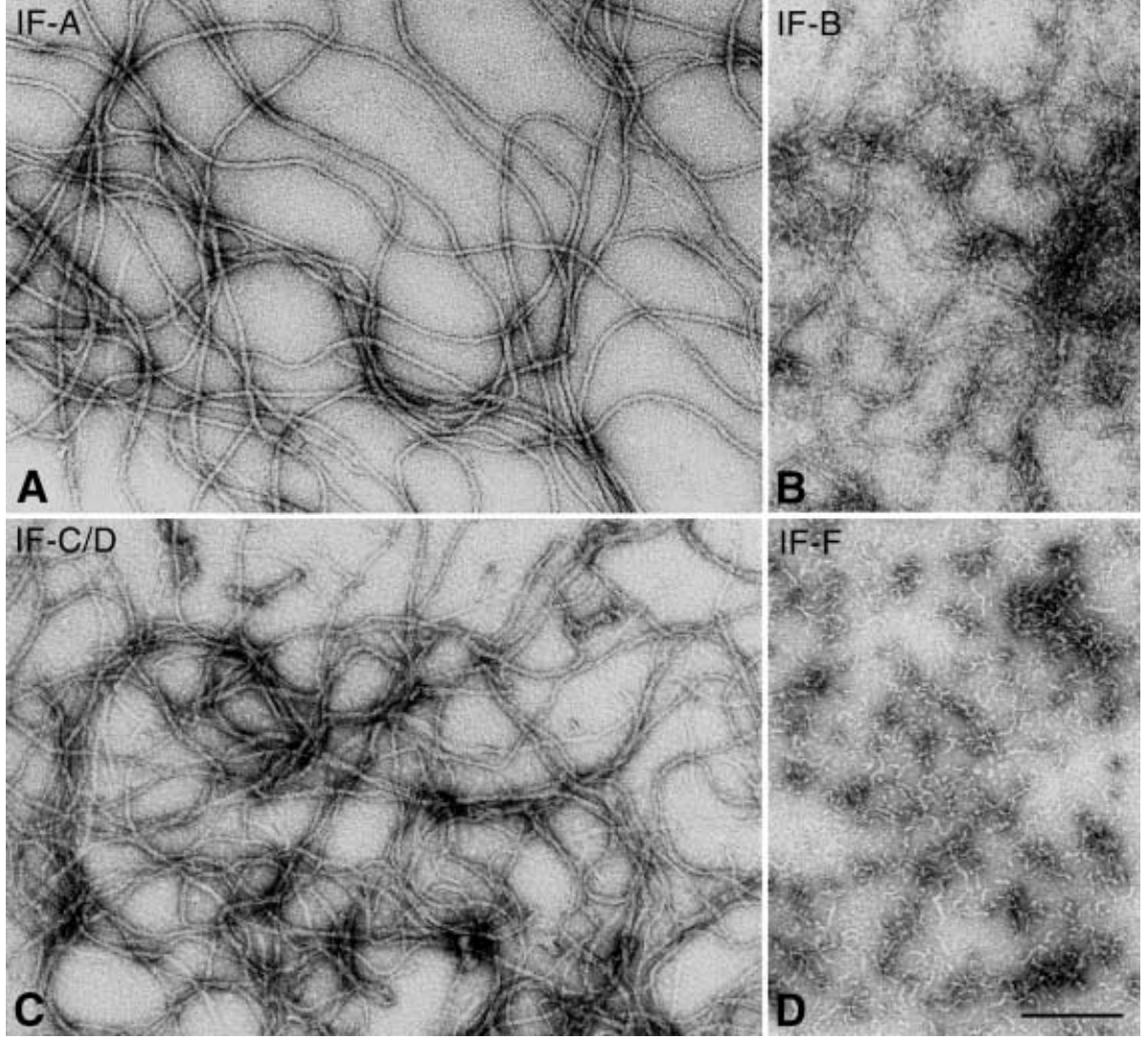

Fig. 3. Electron micrographs of IF assembled from recombinant Ciona IF proteins in vitro. Purified recombinant proteins were dialysed either alone or in equal molar mixtures against filament assembly buffers and negatively stained with $2 \%$ uranyl acetate. Protein IF-A forms long homopolymeric filaments (A). The stoichiometric mixture of proteins IF-C and IF-D provides long heteropolymeric filaments (C). Note that IF-B forms only short filamentous structures (B) while IF-F shows short non-filamentous structures (D). Bar: $200 \mathrm{~nm}$. 


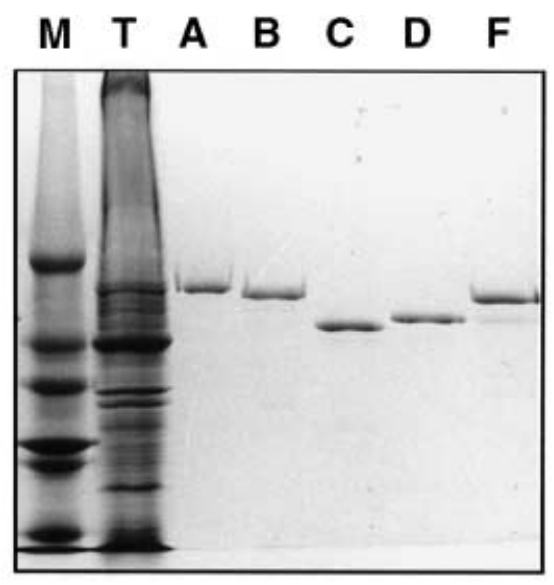

CBB
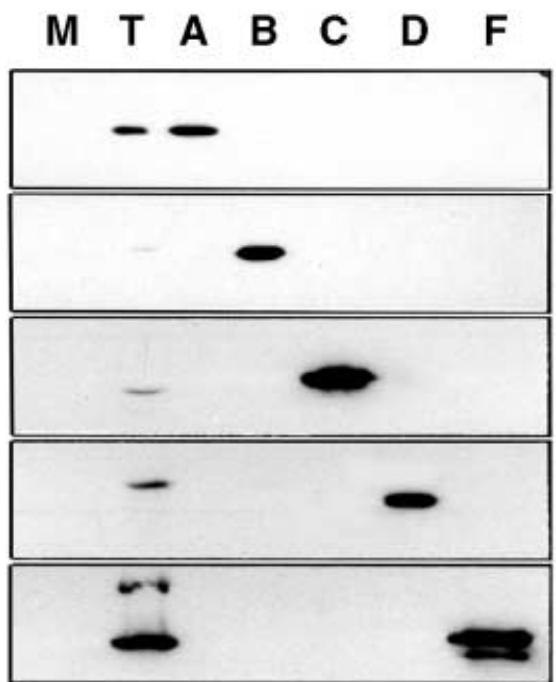

anti-A

anti-B

anti-C

anti-D

anti-F

Fig. 4. Western blot analyses of a total Ciona extract and the recombinant proteins. Total extract $(\mathrm{T})$ and equal amounts of the five purified recombinant Ciona IF proteins (A, B, C, D, F) were separated by $10 \%$ SDS-PAGE and either stained with Coomassie Brilliant Blue (upper panel) or electroblotted on nitrocellulose membranes (lower panels). Blots were immunostained with affinity-purified rabbitderived antibodies as indicated on the right of the individual blot panels. All antibodies detect the corresponding recombinant proteins and a single comigrating band in the total Ciona protein extract (T). Note the weak IF-B protein signal (anti-B) in the total protein extract. Note the slightly higher molecular mass of the IF-D immunoreacting protein band (anti-D) in the total extract compared to the recombinant protein. Approximate molecular masses of the six major marker (M) protein bands are $66 \mathrm{kDa}, 45 \mathrm{kDa}, 36 \mathrm{kDa}, 29 \mathrm{kDa}, 24 \mathrm{kDa}$, and $20 \mathrm{kDa}$.

shown). Expression of proteins IF-A, IF-C and IF-D was also detected at gastrula stages of development, although, we have not yet characterised these IF staining patterns in detail. Protein IF-B was not found at larval stages, while in juveniles it is co-expressed with protein IF-F. Finally, we observed that protein IF-F specifically marks the test cells during larvae stages (Figs. 7G-I) as well as in eggs and all other embryo stages (Figs. 8A, D, F). During metamorphosis, expression of the protein IF-F in test cells is lost, and some cells inside the larval trunk/head begin to show the protein (Figs. 9A-C). These cells may give rise to the tissues seen somewhat later, in

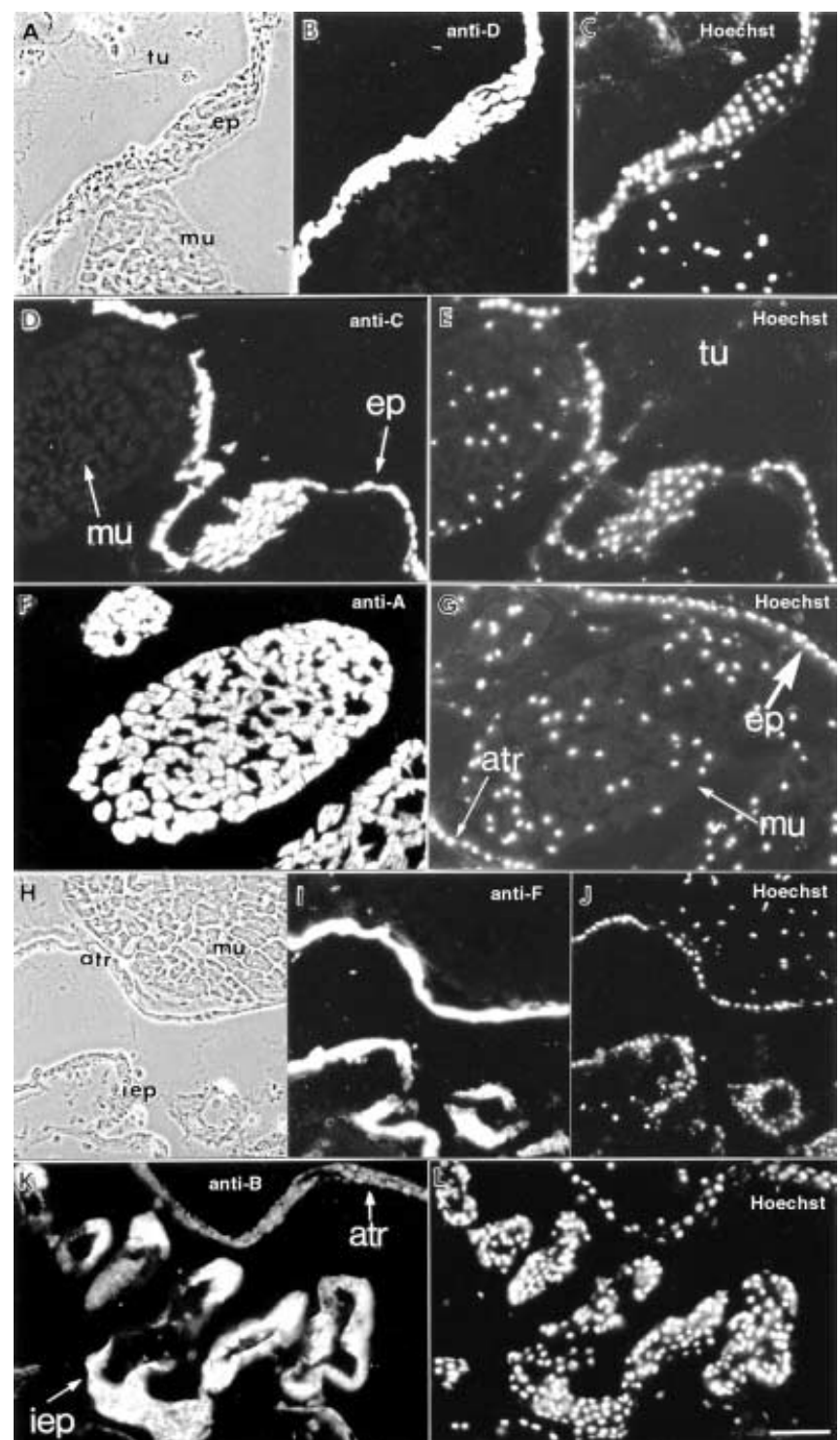

Fig. 5. Immunofluorescence microscopy on cryosections of adult Ciona intestinalis using affinity-purified Ciona IF-specific antibodies. Antibodies against IF-D (anti-D, B) and IF-C (anti-C, D) decorate exclusively the epidermis. The antibody against IF-A stains only the body muscle (anti-A, F) while the anti-IF-F (anti-F, I) and anti-IF-B (anti-B, K) antibodies label the entire interior epithelia. Parallel DNA staining with Hoechst $33258(\mathbf{C}, \mathbf{E}, \mathbf{G}, \mathbf{J}$, and $\mathbf{L})$ was used to facilitate the identification of cells and tissues. The major Ciona tissue types were also visualized in parallel phase-contrast images ( $\mathbf{A}$ and $\mathbf{H})$. Abbreviations are: tu, tunic; ep, epidermis; mu, muscle; atr, atrial epithelium; iep, interior epithelia. Bar: $50 \mu \mathrm{m}$.

post-metamorphic juvenile Ciona, when protein IF-F is found in the internal epithelia, including the pharynx, stomach and intestine (Figs. 9D-F).

\section{Discussion}

We have cloned five cytoplasmic IF proteins using a cDNA library of adult tissue from the tunicate Ciona intestinalis and raised rabbit antibodies, each specific for a single recombinant 


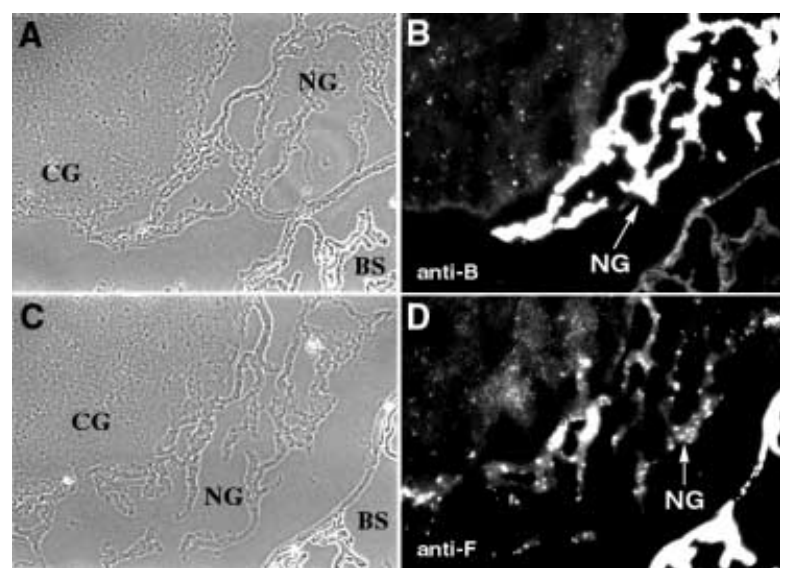

Fig. 6. Immunofluorescence microscopy on cryosections of adult Ciona intestinalis containing neural gland, cerebral ganglion and branchial sac tissues. Antibodies against IF-B (anti-B) strongly decorate the neural gland (NG; B) and weakly the branchial sac (BS) while the cerebral ganglion (CG) seems negative. In contrast, the antibody against IF-F (anti-F) stains strongly epithelia of the branchial sac (D) and weakly the neural gland while the cerebral ganglion was negative. Parallel phase-contrast images (A and $\mathbf{C})$ were used to facilitate the identification of tissues.

IF protein. Four of the Ciona IF proteins resemble the IF proteins $\mathrm{ScA}$ to $\mathrm{ScD}$ cloned previously from a tailbud stage library of the tunicate Styela clava (Wang et al., 2000) while Ciona protein IF-F is a novel tunicate cytoplasmic IF protein. Immunofluorescence microscopy on cryosections of adult Ciona and self-assembly studies of the recombinant proteins confirm and extend earlier results on Styela IF proteins. They identify tunicate IF proteins $\mathrm{D}, \mathrm{C}$ and $\mathrm{A}$ as orthologs of vertebrate type I to III proteins. Thus the muscle-specific protein A forms as a type III ortholog long homopolymeric IF in vitro. The epidermal proteins $\mathrm{D}$ and $\mathrm{C}$ are orthologs of a type I and type II keratin pair and polymerize to obligatory heteropolymeric IF. The finding that protein D can form obligatory heteropolymeric IF with human keratin 8, a type II keratin, directly identifies protein D as keratin I ortholog.

Currently, we cannot relate the remaining two tunicate proteins, IF-B and IF-F, with a particular subfamily of vertebrate IF proteins. Interestingly, in post-metamorphic and adult Ciona proteins IF-B and IF-F are co-expressed in various interior epithelia and in the neural gland (Figs. 5,6,9). Although these expression patterns raise the possibility of a keratin relation, the self assembly studies of the recombinant protein gave no support for this view. Thus future immunoelectron microscopical studies will have to decide whether the coexpression of IF-B and IF-F in interior epithelia and in the neural gland is based on different homopolymeric or mixed heteropolymeric filaments. We note, however, that protein IF-F is strongly present in the test cells of embryos (Fig. 8) which obviously do not express IF-B. In the phylogenetic tree (Fig. 2) proteins IF-B and IF-F are well separated from the D, C and A branches, which correspond to type I to III orthologs. Thus proteins IF-B and IF-F could potentially reflect tunicatespecific IF types. As molecular markers they could help in the future in the analysis of origin and function of the "enigmatic" neural gland. This tissue is closely associated with the cerebral ganglion in all tunicates except larvaceans ((Burighel and Cloney, 1997) and references therein).
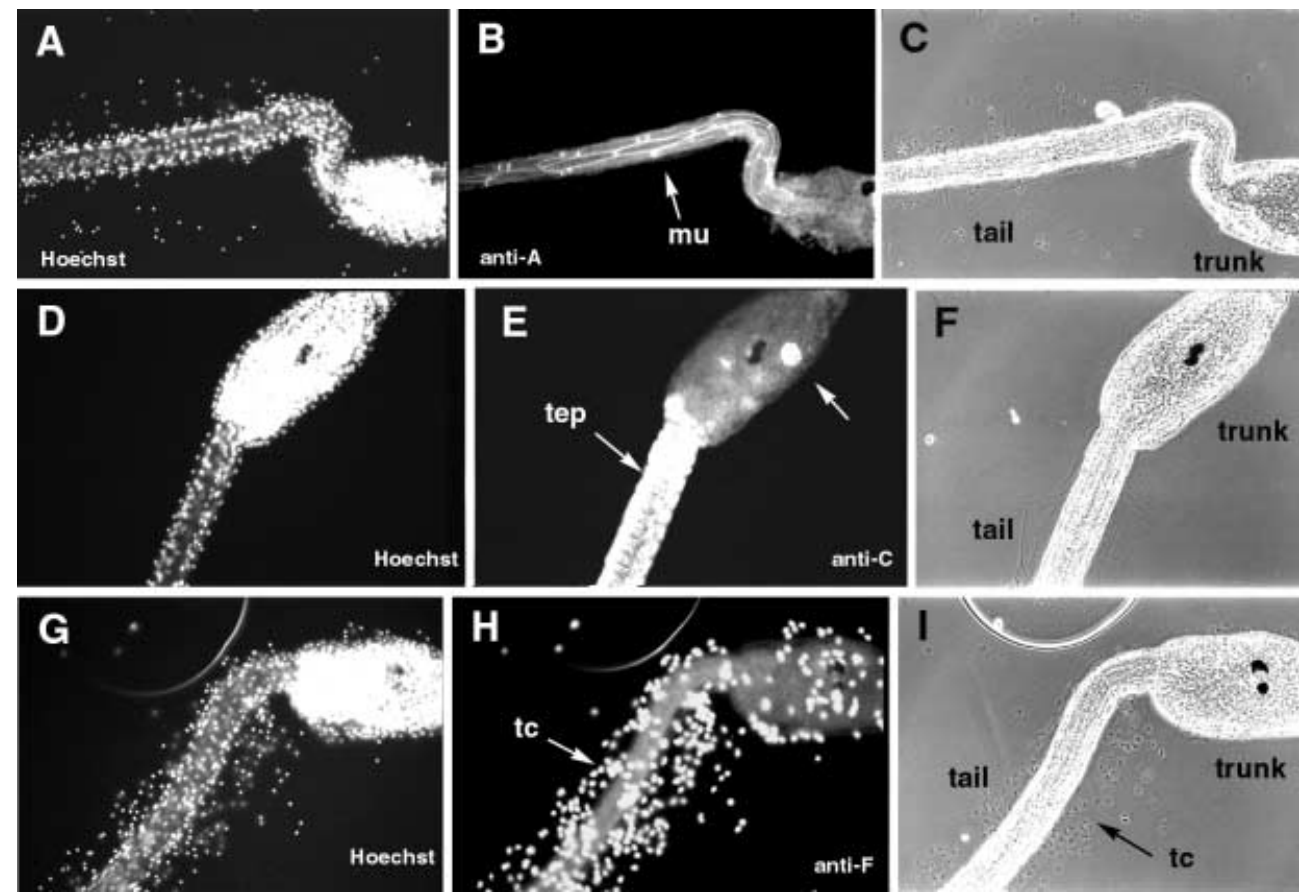

Fig. 7. Immunofluorescence microscopy on whole-mount specimens of Ciona intestinalis pre-metamorphic larvae. The trunk and tail parts of each individual larva were recorded by phase-contrast microscopy $(\mathbf{C}$, F, I). Parallel DNA staining with Hoechst 33258 for the orientation of tissues is shown in (A, D and $\mathbf{G})$. The body muscle $(\mathrm{mu})$ was decorated by the antibody to protein IF-A (anti-A, B). The anti-IF-C antibody

(anti-C) stained the tail epidermis (tep, E) and an unidentified tissue near the sensory organs of the trunk (indicated by an arrow in $(\mathbf{E})$ ) while the trunk epidermis was negative. Protein IF-F is strongly detected by the anti-IF-F antibody (anti-F, $\mathbf{H}$ ) in the test cells (tc) which are located within the larva tunic and tunic-formed fins that cover the entire body surface of the larva. 


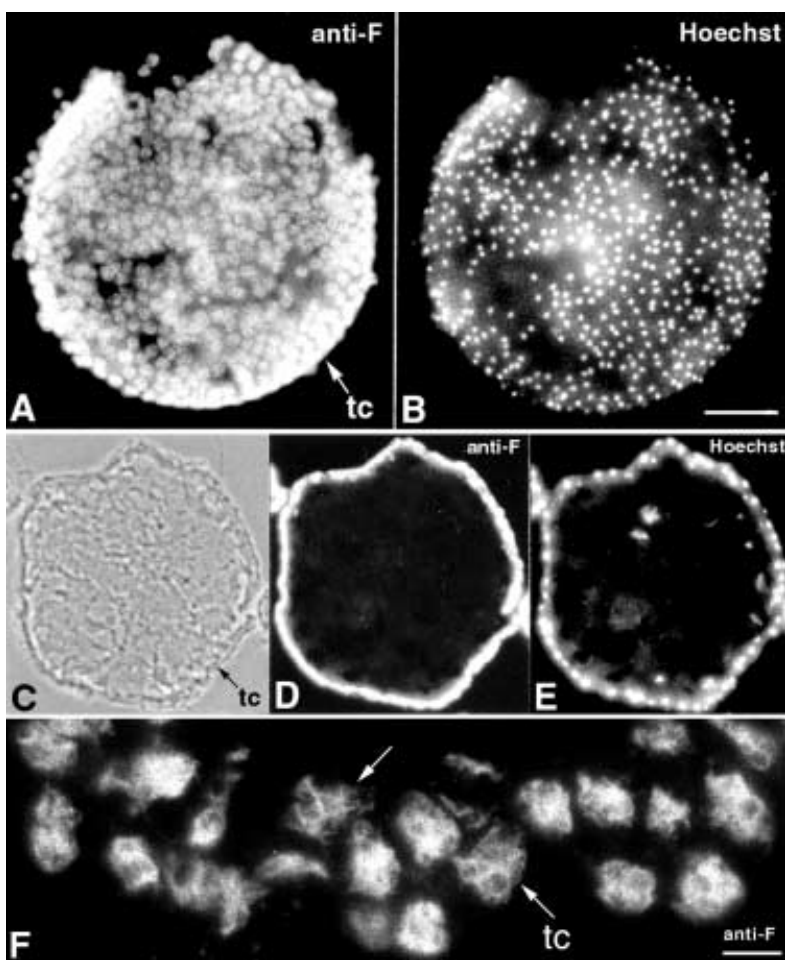

Fig. 8. Immunofluorescence microscopy of Ciona intestinalis eggs and embryos. The whole-mount preparation of an egg (A) and the cryosections of gastrula stage ( $\mathbf{D}$ and $\mathbf{F}$ ) show strong staining of the test cells (tc) by the anti-IF-F antibody (anti-F). As seen at higher magnification (F), the thick bundles (indicated by arrows) are the main structure stained. Parallel DNA staining with Hoechst 33258 is presented in (B and $\mathbf{E}$ ) while $(\mathbf{C})$ represents the corresponding phase-contrast image to $(\mathbf{D}$ and $\mathbf{E})$. Bars: $50 \mu \mathrm{m}$ in $(\mathbf{A}-\mathbf{E})$ and $5 \mu \mathrm{m}$ in $(\mathbf{F})$.

Recently, a large collection of EST sequences from the tailbud stage of Ciona intestinalis was introduced by Satou et al. (2001). When we screened this collection with our five complete IF protein sequences we found EST sequences for proteins IFA, IF-C, IF-D and IF-F. Their accession numbers are
AV680193, AV672741, AV673696, and AV883903, respectively. Among the EST sequences there is also one (accession number AV674774) which is derived from the nuclear lamin L2 previously reported (Riemer et al., 2000; accession number AJ251957). So far we have not found type IV neurofilament IF proteins in the tunicates Ciona and Styela (Wang et al., 2000), and these have also not been found in the cephalochordate Branchiostoma (Karabinos et al., 2000). Also, none of the Ciona IF proteins reported here are expressed in the ganglion, while neural expression of keratin orthologs has been found for Branchiostoma (Karabinos et al., 2000, 2001b). Continuation of the Ciona EST sequence programme raises the possibility that more cytoplasmic IF proteins can be identified and characterised in Ciona. This speculation is indicated by the known size of the cytoplasmic IF multigene family established in other invertebrate phyla. The genome of the nematode $C$. elegans contains 11 such genes (Karabinos et al., 2001a) and the cephalochordate Branchiostoma has at least 13 genes for cytoplasmic IF proteins (Karabinos et al., 2000).

It is generally thought that the cephalochordate Branchiostoma is the closest relative of the vertebrates (Luke and Holland, 1999; Swalla et al., 2000) while the urochordates are the most remote phylum of the chordates. This relation is also indicated by the organisation of the IF genes. Tunicate (Fig. 2C) and cephalochordate IF genes (Karabinos et al., 2000) have intron patterns related to vertebrate type I to III genes. In general the homology in intron patterns is better conserved in vertebrate and cephalochordate genes than in tunicate genes. For instance all five tunicate genes display an intron in the region corresponding to the amino-terminal head domain. Vertebrate IF genes and the currently fully characterized Branchiostoma IF genes all lack an intron in the head domain. Taken together, the tunicates appear to have cytoplasmic IF proteins which are orthologs of the vertebrate IF groups I-III, but also IF proteins that do not fit into these classes. However, the intron positions of all tunicate IF genes are conserved with vertebrate type I to III genes, pointing to a common evolutionary origin.

Use of synthetic peptides derived from the five IF protein sequences allowed us to prepare rabbit antibodies. As shown by
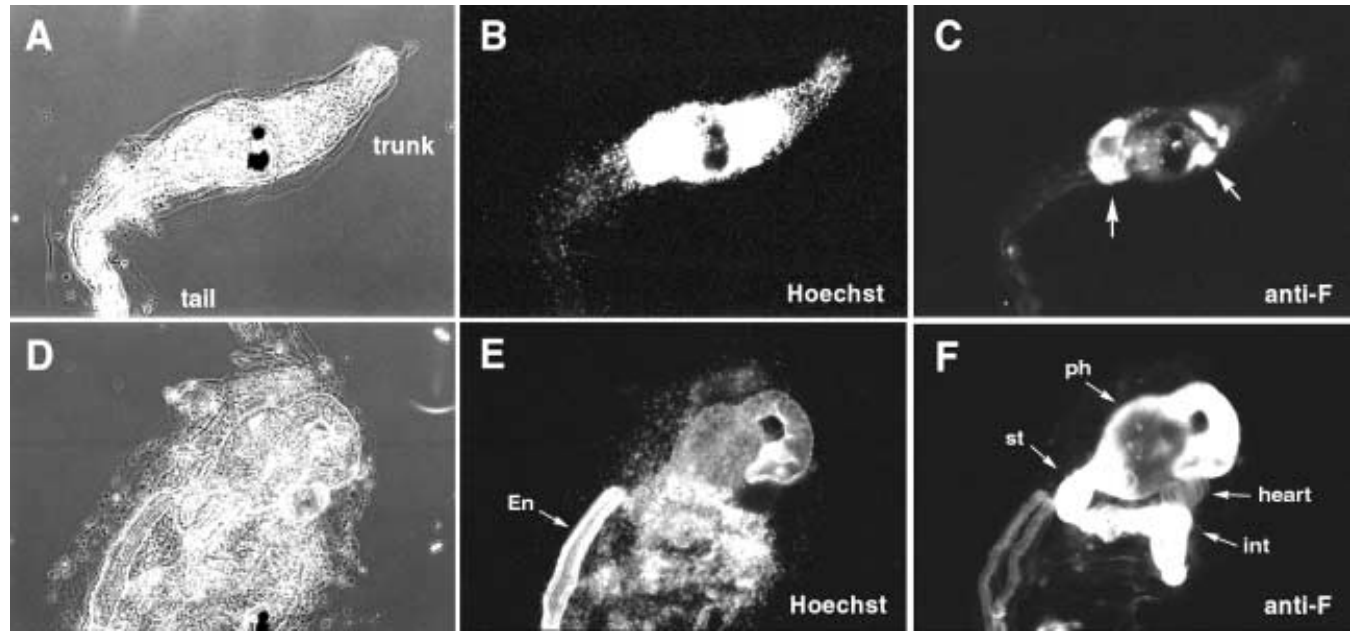

Fig. 9. Immunofluorescence microscopy on whole-mount specimens of metamorphic Ciona intestinalis larvae and of juveniles with antiCiona IF-F antibody (anti-F). Both specimens were simultaneously recorded by phase-contrast optics $(\mathbf{A}, \mathbf{D})$ and also labeled with Hoechst 33258 to visualize DNA (B, E). In the metamorphic larva the IF-F

protein is strongly expressed in some unidentified tissues of the trunk which are marked by arrows in (C). After metamorphosis protein IF-F is found in the entire interior epithelia (F) including pharynx (ph), stomach (st) and intestine (int). The endostyle (En) and the heart (heart) seem negative. 
immunoblotting of the recombinant proteins each of these antibodies is specifically directed against a single Ciona cytoplasmic IF protein (Fig. 4). We have used these antibodies in immunofluorescence microscopy on different developmental stages of Ciona (Figs. 7-9). The pre-metamorphic larva shows an interesting staining pattern for the epidermal keratins IF-C and IF-D. These are only detected in the tail epidermis and not in the epidermis of the trunk. Interestingly in tunicates, tail (posterior) epidermis is derived from posterior animal blastomeres, b4.2, of the 8-cell stage embryo, whereas trunk (anterior) epidermis comes from the anterior animal, a4.2 blastomeres (Nishida and Satoh, 1985). It would therefore be interesting to determine in the future whether the IF-C and IFD keratin staining pattern described corresponds to the different origins of posterior and anterior epidermis. In contrast in juveniles and in adult animals proteins IF-C and IF-D are coexpressed in the entire epidermis, which remains a simple epithelium. An unexpected result was provided by the antibody to the IF-F protein. While the staining patterns of proteins IF-F and IF-B overlap in post-metamorphic and adult interior epithelia as well as in the neural gland (Figs. 5,6,9), protein IF-F is found in the absence of IF-B in the test cells of egg, gastrula, neurula, and the pre-metamorphic larva (Figs. 7H,8). Test cells of Ciona, one of the two accessory cell groups (follicle cells and test cells) of the oocyte, are small round-shaped cells located in the innermost layer of the embryo membrane, which encloses the egg (Satoh, 1994; Burighel and Cloney, 1997). A single oocyte of Ciona has approximately 1000-1200 test cells (Deno, 1987). Various studies suggested that test cells may play important roles such as to nourish the oocyte, to produce hatching enzymes and to function in the formation of the larval tunic ((Satoh, 1994) and references therein; (Sato and Morisawa, 1999)) but the origin of the test cells is still not understood. One view assumes that the eggs and follicle cells of Ciona are derived from the germinal epithelium while the test cells are differentiated from the inner follicle cells (Satoh, 1994; Sugino et al., 1987). Thus, our finding that the IF-F protein is expressed in test cells may become in the future a valuable differentiation marker to analyze the derivation of the test cells.

Acknowledgements. We thank Tomma Eisbein, Susanne Brandfass, Jürgen Schünemann and Uwe Plessmann for expert technical assistance. Dr. Billie J. Swalla (University of Washington, Seattle, USA) kindly provided a gastrula cDNA library from Molgula oculata. We thank Dr. Charles C. Lambert (California State University, Fullerton, USA) for helpful discussions.

\section{References}

Burighel, P., Cloney, R. A. (1997): Urochordata: Ascidiacea. In: F. W. Harrison, E. E. Ruppert (eds.): Microscopic anatomy of invertebrates. Wiley-Liss Inc., New York, Vol. 15, 221-247.

Corbo, J. C., Di Gregorio, A., Levine, M. (2001): The ascidian as a model organism in developmental and evolutionary biology. Cell 106, 535 538 .

Deno, T. (1987): Autonomous fluorescence of eggs of the ascidian Ciona intestinalis. J. Exp. Zool. 241, 71-80.

Dodemont, H., Riemer, D. Ledger, N., Weber, K. (1994): Eight genes and alternative RNA processing pathways generate an unexpectedly large diversity of cytoplasmic intermediate filament proteins in the nematode Caenorhabditis elegans. EMBO J. 13, 2625-2638.

Dodemont, H., Riemer, D., Weber, K. (1990): Structure of an invertebrate gene encoding cytoplasmic intermediate filament pro- teins: implications for the origin and the diversification of IF proteins. EMBO J. 9, 4083 - 4094.

Erber, A., Riemer, D., Bovenschulte, M., Weber, K. (1998): Molecular phylogeny of metazoan intermediate filament proteins. J. Mol. Evol. 47, $751-762$.

Fuchs, E., Weber, K. (1994): Intermediate filaments: Structure, dynamics, function and disease. Annu. Rev. Biochem. 63, 345-382.

Herrmann, H., Aebi, U. (2000): Intermediate filaments and their associates: multi-talented structural elements specifying cytoarchitecture and cytodynamics. Cuur. Opin. Cell Biol. 12, 79-90.

Hesse, M., Magin, T. M., Weber, K. (2001): Genes for intermediate filament proteins and the draft sequence of the human genome: novel keratin genes and a surprisingly high number of pseudogenes related to keratin genes 8 and 18. J. Cell Sci. 114, 2569-2575.

Hudson, C., Lemaire, P. (2001): Induction of anterior neural fates in the ascidian Ciona intestinalis. Mech. Dev. 100, 189-203.

Irvine, A. D., McLean, W. H. (1999): Human keratin diseases: the increasing spectrum of disease and subtlety of the phenotypegenotype correlation. Br. J. Dermatol. 140, 815-828.

Karabinos, A., Riemer, D., Panopoulou, G., Lehrach, H., Weber, K. (2000): Characterisation and tissue-specific expression of the two keratin subfamilies of intermediate filament proteins in the cephalochordate Branchiostoma. Eur. J. Cell Biol. 79, 1-10.

Karabinos, A., Schmidt, H., Harborth, J., Schnabel, R., Weber, K. (2001a): Essential roles for four cytoplasmic intermediate filament proteins in Caenorhabditis elegans development. Proc. Natl. Acad. Sci. USA 98, 7863-7868.

Karabinos, A., Wang, J., Wenzel, D., Panopoulou, G., Lehrach, H., Weber, K. (2001b): Developmentally controlled expression pattern of intermediate filament proteins in the cephalochordate Branchiostoma. Mech. Dev. 101, 283-288.

Luke, G. N., Holland, P. W. (1999): Amphioxus type I keratin cDNA and the evolution of intermediate filament genes. J. Exp. Zool. 285, 50-56.

Nishida, H., Satoh, N. (1985): Cell lineage analysis in ascidian embryos by intracellular injection of a tracer enzyme. II. The 16- and 32-cell stages. Dev. Biol. 110, 440-454.

Parry, D. A. D., Steinert, P. M. (1995): Intermediate filament structure. Springer, New York.

Pruss, R. M., Mirsky, R., Raff, M. C., Thorpe, R., Dowding, A. J., Anderton, B. H. (1981): All classes of intermediate filaments share a common antigenic determinant defined by a monoclonal antibody. Cell 27, 419-428.

Riemer, D., Dodemont, H., Weber, K. (1992): Analysis of the cDNA and gene encoding a cytoplasmic intermediate filament (IF) protein from the cephalochordate Branchiostoma lanceolatum; implications for the evolution of the IF protein family. Eur. J. Cell Biol. 58, 128-135.

Riemer, D., Karabinos, A., Weber, K. (1998): Analysis of eight cDNAs and six genes for intermediate filament proteins in the cephalochordate Branchiostoma reveals differences in the multigene families of lower chordates and the vertebrates. Gene 211, 361-373.

Riemer, D., Wang, J., Zimek, A., Swalla, B. J., Weber, K. (2000): Tunicates have unusual nuclear lamins with a large deletion in the carboxyterminal tail domain. Gene 255, 317-325.

Riemer, D., Weber, K. (1998): Common and variant properties of intermediate filament proteins from lower chordates and vertebrates; two proteins from the tunicate Styela and the identification of a type III homologue. J. Cell Sci. 111, 2967-2975.

Sato, Y., Morisawa, M. (1999): Loss of test cells leads to the formation of new tunic surface cells and abnormal metamorphosis in larvae of Ciona intestinalis (Chordata, Ascidicacea). Dev. Genes Evol. 209, $592-600$.

Satoh, N. (1994): Developmental biology of ascidians. Cambridge University Press, New York.

Satou, Y., Takatori, N., Yamada, L., Mochizuki, Y., Hamaguchi, M., Ishikawa, H., Chiba, S., Imai, K., Kano, S., Murakami, S. D., Nakayama, A., Nishino, A., Sasakura, Y., Satoh, G., Shimotori, T., Shin-I, T., Shoguchi, E., Suzuki, M. M., Takada, N., Utsumi, N., Yoshida, N., Saiga, H., Kohara, Y., Satoh, N. (2001): Gene expression profiles in Ciona intestinalis tailbud embryos. Development 128, $2893-2904$. 
Sugino, Y. M., Tominaga, A., Takashima, Y. (1987): Differentiation of the accessory cells and structural regionalization of the oocyte in the ascidian Ciona savignyi during early oogenesis. J. Exp. Zool. 242, $205-214$.

Swalla, B. J., Cameron, C. B., Corley, L. S., Garey, J. R. (2000): Urochordates are monophyletic within the deuterostomes. Syst. Biol. 49, 52-64.

Swofford, D. L. (1998): PAUP. Phylogenetic analyses using parsimony (and other methods), Ver. 4 (Sinauer, Sunderland, MA).
Wang, J., Karabinos, A., Schünemann, J., Riemer, D., Weber, K. (2000): The epidermal intermediate filament proteins of tunicates are distant keratins; a polymerisation-competent hetero coiled coil of the Styela D protein and Xenopus keratin 8. Eur. J. Cell Biol. 79, 478-487.

Weber, K., Plessmann, U., Ulrich, W. (1989): Cytoplasmic intermediate filament proteins of invertebrates are closer to nuclear lamins than are vertebrate intermediate filament proteins; sequence characterization of two muscle proteins of a nematode. EMBO J. 11, 3221 3227. 